\section{Permafrozen Peat Sampling - Dynamite and Chain-Saw}

The recovery of specimens of frozen peat for purposes of palynology and radiocarbon dating is notoriously difficult. A recent development by the Geological Survey of Canada has been the attachment of a powerdrive to the SIPRE ice-borer which allows the rapid recovery of 3 inch $(7.6 \mathrm{~cm}$.) diameter cores from frozen ground. The borer weighs I05 lbs. (c $48 \mathrm{~kg}$.) and the motor 26 or $85 \mathrm{lbs}$. ( 12 or $39 \mathrm{~kg}$.) depending on the type employed. ${ }^{1}$ This equipment does not entirely fulfil the requirement for a small lightweight sampler which is easily portable by one man over long distances through rough country.

An unpremeditated encounter with a permanently frozen peat bank in subarctic Canada led the author to employ explosives for sampling, after work with a hammer and chisel had provided samples big enough for pollen analysis but not for radiocarbon dating. The explosion of two dynamite charges at the base of the peat face resulted only in the exposure of a fresh (frozen) surface. A third charge shattered the peat face so that the vertical bank was faced with partially-broken lumps of frozen peat. These were in situ, but they could then be prised away from the parent body after the depth below surface had been noted. In this fashion a sequence of irregularly-shaped peat blocks was obtained which gave an approximately vertical and almost continuous peat section from the upper permafrost surface to the minerogenic base (a total depth of about one metre). This type of sampling is considered to be a hit-or-miss method, with no guarantee of success, and it is not recommended save as a last resort. Users are advised that inhalation of the explosion gases which linger at the site for some minutes after detonation may lead to intense headaches lasting many hours.

Subsequently it was found that a conventional $5 \frac{1}{2}$ horsepower chain-saw was capa- ble without adaptation of cutting frozen peat without difficulty and with close control. I am not aware of the previous use of this tool for peat sampling, but I make no claim for originality in its employment. I merely observe that I was once unaware of its potential and I suspect that this ignorance may be widespread. The chain-saw is light in weight ( 15 lbs. or $7 \mathrm{~kg}$.), inexpensive (c. 150 U.S. dollars), small, and is easily obtainable from general stores throughout the United States and Canada. It allows the easy excavation of frozen peat monoliths big enough for $\mathrm{C}^{14}$ and plant macrofossil analysis (c. 20 to 25 $\mathrm{cm}$. square) provided that there is an exposed peat face.

Where no exposed peat bank exists it is possible to use explosives to excavate a hole in the peat, thus providing an exposure which may be sampled by chain-saw. The shallowness of peat in areas subject to permafrost (often less than two metres of organic accumulation for the post-glacial in Arctic North America) makes such excavation relatively easy.

\section{ACKNOWLEDGMENT}

The research was supported by Atmospheric Sciences Division, National Science Foundation (GP-5572x).

Harvey Nichols, PH.D. DEPARTMENT OF METEOROLOGY UNIVERSITY OF WISGONSIN

1 hughes, O. L. and J. TERASMAE, I963. SIPRE ice-corer for obtaining samples from permanently frozen bogs. Arctic I6: 27 I-72.

\section{Correction}

The floor of the Arctic Ocean: Geographic Names. Arctic, Volume 19, Number 3, Fig. 2 (Frontispiece) and Table I, item 16, page 2r 8: Markarov Basin should read Makarov Basin. 